depositions. However, the quality defects of the hypertrophied musculature, more marked in the Pietrain than in the Belgian Landrace (Dumont, 1974) might necessitate a particular study of the nutritional conditions during the very early differentiation of the 2 types of musculatures.

- The parameters for the estimation of the degrees of fatness or leanness during growth are variable according to breeds when considering the thicknesses and areas of fat and muscle measured on the dorso-lumbar cutting ( $13^{\text {th }}$ and $\mathrm{I}_{4}$ th rib). Checking of fatness at $60 \mathrm{~kg}$ and of eye muscle areas at $80 \mathrm{~kg}$ would give optimum estimations of the anatomical composition according to breeds. On the other hand, at slaughter, the loin cye area represents a poor estimation of the degree of leanness in the breeds : Landrace Français $(+0.54)$ or Landrace Belge $(+0.69)$, whereas this estimation is accurate in the Pietrain breed $(+0.99)$. The loin eye thickness represents a measure of the varying degree of compactness of the lean mass.

At the commercial stage of $95 \mathrm{~kg}$, classification criteria might be based on the previsional value of the ratio $\frac{\text { loin }}{\text { backfat }}$ for the estimation of the ratio $\frac{\text { muscle }}{\text { fat }}$ in the different breeds $(r=0.93$ to 0.95$)$. Forecasting of the lean content of the carcass by this criterion $\left(\frac{\text { loin }}{\text { backfat }}\right)$, as in the case of the densimetric classification, however leads to consideration of the grades related to $\frac{\text { the muscle }}{\text { bone }}$ ratios of the different breeds. A special codification of carcasses from hypermuscled breeds appears to be necessary for objectively estimating the lean percentage by conformation scores (grading of the E. E. C.)

\title{
Comparative studies of ham characteristies in Landrace Français, Landrace Belge and Pietrain pigs
}

\author{
B. L. DUMONT and G. ROY \\ Laboratoire de Recherches sur la Viande, I. N.R. A., C. N. R. Z., \\ 78350 Jouy en Josas
}

Anatomical composition of ham (percentages of muscle, fat, bone and skin ; distribution of different muscles) has been studied in 16 females of the following breeds : Landrace Français $(L F)$, Landrace Belge $(L B)$ and Pietrain $(P)$. The average weight of ham in each breed was $8169 \mathrm{~g}$ for LF, $8754 \mathrm{~g}$ for $L B$ and $8815 \mathrm{~g}$ for $P$. A significant effect of the breed was found for percentage of muscle, bone, external fat. The commercially edible part of the ham was $69,08 \mathrm{p}$. Ioo in $L F$, 74,62 p. 100 in $P$ and 74,82 p. 100 in $L B$. The percentage of the most interesting muscles (adductor, semitendinosus, semimembranosus, biceps femoris) was higher in $L B$ and $P$ than $L F$. Meat characteristics (color, $\mathrm{pH}$, water holding capacity) were measured in 8 locations throughout the ham. Pietrain pigs had lower $\mathrm{pH}$ values and water holding capacities than $L F$ and $L B$. Within each breed a rather large variation was found for all characteristics studied. Shear forces of semimembranosus and biceps femoris were not different between the three breeds.

Landrace Belge seemed to be the best breed of the 3 for ham processing. It is also suggested that muscular hypertrophy does not affect in the same way the Landrace Belge and the Pietrain breed, which could support the hypothesis that muscular hypertrophy is not governed by the same genetic factors in both breeds. 